\title{
Implementing an Open Source Catalog in a Consortial Environment
}

Evan E. Boyd, United Lutheran Seminary

\begin{abstract}
The Eastern Cluster of Lutheran Seminaries (Lutheran Theological Southern Seminary and United Lutheran Seminary) have had a joint library catalog between their three libraries for over 18 years. This has allowed for inter-campus lending, some shared purchases, and joint collection development. After using a shared instance of Voyager for 17 years, the Cluster knew it was time to upgrade. During the 2018-19 school year, the Cluster researched alternative software and ultimately selected the open source tool Koha, hosted by Equinox Open Library Initiative. This paper explains the reasons for change, the selection process, key decisions in the install process, lessons learned, and an overall assessment of the transition to Koha.
\end{abstract}

During the 2018-19 school year, United Lutheran Seminary and Lutheran Theological Southern Seminary of Lenoir-Rhyne University entered into a process to replace their shared integrated library system with a modern, currently-supported system that better met the two institutions' needs. This process began with an assessment of current needs, discussions with vendors, and final selection of the best system to meet the Cluster's needs: Koha with Equinox Open Library Initiative. This essay will walk the reader through the assessment \& selection process as well as some information about the installation and assessment of the new software's ability to meet the Cluster's needs.

\section{BACKGROUND OF THE EASTERN CLUSTER}

United Lutheran Seminary Library is a multi-campus library composed of the Krauth Memorial Branch Library, A. R. Wentz Branch Library, and the archives of Region 8 of the Evangelical Lutheran Church in America. ULS Library partners with Lutheran Theologi- 
cal Southern Seminary of Lenoir-Rhyne University for a consortial catalog as well as intercampus delivery of books and articles. ULS and LTSS consider their collections a joint collection, or "one library under three roofs." This partnership has been the longest-lasting program of the Eastern Cluster of Lutheran Seminaries (the Cluster). For more information on this history, I highly recommend reading David Wartluft (2002) as well as Karl Krueger (2007).

\section{THE PROBLEM}

When I arrived at ULS Library to manage the new institution's two campus libraries, I immediately recognized that the Eastern Cluster Libraries were in need of either a new library catalog or more trained staff on the catalog. Key issues with the current system included:

- Voyager had essentially reached end of life. No major features were coming out and Ex Libris was trying to get everyone onto their newer product, Alma.

- Across three libraries, only one staff member was still fully trained on the software. ${ }^{1}$

- The software was inadequate to the needs of a 21st-century library: URLs in the OPAC were not permalinks; automatic logout from the staff client after 10 minutes of no use; a software client was required to operate staff functions.

- A central feature of the Cluster is inter-campus lending. However, patrons could not perform unmediated requests; a staff member had to manually enter their paper (or emailed) requests.

- Notices had to be produced manually and Voyager had no builtin mailer daemon for sending those messages; separate mail server had to be provided by ULS's IT staff.

- The OPAC was not mobile friendly, making on-the-fly lookups while in the book stacks frustrating.

The Cluster directors came to agreement that a change was needed. Initially, the Cluster approached Ex Libris to train all library staff on Voyager, hoping that more training would reveal ways the Cluster staff could better utilize the software. Ex Libris rebuffed the request, pointing to the manual rather than offering custom training. Ultimately, they recommended replacing Voyager with Ex Libris Alma 
with Primo or Summon; they had said the costs would be similar to current costs.

\section{NEW SYSTEM PRIORITIES}

At this point, the directors knew they needed to look at what other options were available. The directors developed a priority list of needed features of the new system:

- Designed for consortial and multi-branch use.

In the beginning, Gettysburg, Philadelphia, and Southern shared circulation policies. Over the years, multiple library directors' varied interest in the "One Library/Three Roofs" model led to distinct policies being developed at each campus. While Gettysburg and Philadelphia now have matching policies, Southern still varies. Being able to allow for varied circulation rules continues to be important.

- Designed for inter-campus lending and "floating collections."

Under the "One Library/Three Roofs" model, patrons in Philadelphia are able to request materials from Gettysburg or Southern to be delivered to Philadelphia or delivered to their home. Not only that, but books sent to another campus are expected to stay there until requested back by their home library. This system has been successful over time but, because of the way Voyager was originally set up, this process was completely manual. Paper requests were accepted at the library front desk and circulation staff would message the lending library to have them mail the book on. In an ideal world, staff wanted patrons to be able to make unmediated requests, avoiding reliance on their own staff to submit the request.

- Must have a course reserves module.

- OPAC

A web interface must be modern, easily-updatable, and customizable by someone with a basic knowledge of HTML standards. One of the problems the Cluster had with Voyager was that libraries wanted to make e-books easily discoverable. However, Voyager's OPAC wasn't designed to have its interface easily updated. To make the slightest public interface change required changing multiple data tables on the server, rather than being 
easily manipulated with CSS or other common HTML standards anyone could master.

- Hosted by a reputable vendor with active development. Voyager was in use by the Cluster for almost eighteen years and LTSS first went live with Voyager earlier than that. The Cluster probably would have kept on with it longer, had it not been glaringly obvious that Ex Libris was preparing to end support with it. This was hammered home for the Cluster when it had requested to purchase videoconference training sessions and was rebuffed by Ex Libris's support team with links to the software manual. Just like with Voyager, the new software would be expected to be in use for a long time with regular updates. The new software had to be stable, with a large user base, and actively being developed.

- Easy-to-learn, web-based software.

Voyager is not an easy piece of software to utilize, whether you are just a student worker checking out books or a full-time cataloguer. Because of this, the directors wanted software that could be learned fairly easily and was web-based, as the staff had several bad experiences with the Voyager desktop software. In addition, being web-based meant that staff could perform duties away from the office on any computer (a feature that has been very useful during the 2020 COVID-19 pandemic).

\section{- Reduces overall costs.}

\section{REACHING OUT TO VENDORS \& QUOTES}

Once the team had this list ready, I made initial contacts with Ex Libris, Innovative, OCLC, and Equinox Open Library Initiative.

Innovative informed us they were only selling Sierra and no longer offered their Virtua software, which, based on marketing, seemed a better fit for the Cluster. Some staff members' personal experiences with Sierra were filled with the same issues as the experience with Voyager. Ex Libris and OCLC both gave presentations; the directors saw the many great advantages of their products (Alma and WMS) and were initially hopeful that quotes would be similar to current costs rather than an increase. Sadly, both vendors arrived at similar price points, wherein annual costs would have increased by 
fifty-six percent and the initial set up fee would be quite high—as much as the annual hosting fee.

In my previous work experience, I had used a fork of Koha at Chicago Theological Seminary. Considering open source software was important to me, as I had a good experience with Koha, but I also wanted to see what else was out there. At this time, the FOLIO project did not have a complete project to demo so they were not considered. Both Koha and Evergreen and their various softwareas-a-service vendors were researched.

Equinox Open Library Initiative is both an open source software developer and hosted software vendor. They are known for having been created by the initial developer of Evergreen (Equinox Initiative 2020), an open source integrated library system that was developed for use by library consortia from day one (Weber 2006). In the last few years, Equinox had branched out to hosting Koha, as well. The Cluster reached out to them, shared its needs, and they assessed that Koha best met those needs, as Evergreen did not yet have a course reserve module.

After a demo, quotes for annual hosting and installation were received. The Cluster members were shocked that Equinox's annual hosting fee would be 10\% of current costs with Ex Libris Voyager. In fact, the installation and data conversion costs would be roughly what was paid for Ex Libris Voyager each year. This meant the Cluster could move forward without any significant impact on the Cluster's budget!

After final approval from the Cluster's board, contracts were signed with Equinox in March 2019. In April, they were granted access to the data tables in Voyager. In May, the initial project management meeting was held to go over major concerns and to take the staffs through the process of the various pieces of data needing to be reviewed. The new Eastern Cluster Catalog Online (ECCO) went live on August 22, 2019. Working with Equinox, the Cluster was able to get from the signing date to fully running in slightly less than six months. This was perfect, as the Ex Libris Voyager contract ended in October, which was just enough time for us to work through Koha and fix any problems. 


\section{GENERAL ISSUES WITH KOHA}

Throughout this process, the Cluster knew there were some messy things in Voyager that needed to be resolved. In addition, some aspects of Koha were not fully understood until after either the testing server was in place or the final go-live happened. Some of the major problems include:

\section{- Too many item types.}

In the past, whenever a new shelving location was created, a corresponding item type was created. The Cluster simplified this, so that it could get by with as few item types as possible. This simplification makes updating circulation policies somewhat easier. While the Cluster did greatly reduce the number of item types, from 100 down to 23, it is possible a few more could have been eliminated.

- Permanent location - current location - shelving location. Koha displays current location information in an odd way. For instance, on a search result page, Koha only indicates if something is available and what branch it is at. This information lacks the most important detail: the shelving location, as each branch has a number of closed stacks. Patrons can get frustrated by this.

\section{- Loss of the MFHD.}

Voyager uses the MARC Format for Holdings Data, or MFHD, as well as an item record for physical items. MFHDs can be used to create local holdings information, in particular periodical holdings information as well as series information. In addition, bibliographic records can be added to Voyager and are findable without item records but with MFHDs. Koha has a two-level structure: there is the bibliographic record and there is the item record. While bibliographic records can be searched without item records, one cannot narrow by owning library without an item being attached.

There are other related concerns we're still working on, such as 5,000 records with no items attached, some of which are old acquisitions/order records for the old acquisitions data as well as bibliographic records for items that were withdrawn. 


\section{- Item and branch info affects display and search.}

In order to narrow search results by format or location, Koha utilizes item data. Since there are no MFHDs to also provide that data, every bibliographic records needs an item attached, regardless if there is a physical item. In addition, ULS purchases e-books for its entire student population and not just for a single campus. These factors all affect the number of "branches" that exist in the catalog. In order to make electronic resources stick out, three additional library "branches” have been added.

- The Cluster eResources Branch was created for any open access e-resources added to the catalog.

- The ULS eResources Branch was created for any paid content ULS added to the catalog.

- Southern eResources Branch was created for Southern resources after it was noticed that ULS and Cluster e-resources are more visible than Southern's, as the basic branch location designation in a search results page doesn't cue the user in to the fact that something is an e-book.

\section{LONGER-TERM ISSUES STILL BEING RESOLVED}

While the Cluster has resolved most of the major issues since installing Koha, there are some lingering issues:

\section{- Periodicals information.}

MFHD information for periodicals and other serial resources were not necessarily transferred correctly into Koha. In addition, the Cluster staff didn't quite understand what relevant fields would be most easily seen in Koha, so some of the info that did transfer is hidden or shows up multiple times in the same record. Cody Swisher, public services librarian in Gettysburg, is slowly working his way through periodicals to update holdings information. Luckily, Koha has robust, easy-to-use reporting tools that have made identifying records in need of work simple. Those reports can be used to create downloads of problematic records that can be edited in MarcEdit and reuploaded, overlaying the problematic record.

\section{- E-books owned by more than one library.}

Koha has a very easy-to-use batch upload tool. Unfortunately, 
that tool does not allow you to run record updates-that is, compare the current record and the incoming version of the record and only update the current record with new information. This is mostly not an issue; however, it does mean that, currently, there are duplicate bibliographic records in the system, as ULS and Southern use different authentication systems. Eventually, staff will test and develop a process to download records needed, update in MarcEdit, and then reupload with both institutions' 856 fields.

\section{QUESTIONS FROM CONFERENCE ATTENDEES}

Q: How did you handle duplicate entries while migrating your data?

A: The Cluster sub-contracted with Backstage Library Works through Equinox to have all records updated with current subject headings and added RDA elements. Record duplication was also checked for but there was very little.

Q: Would using Koha for your consortium work as well ifyou were not so closely integrated in circulation and cooperation?

A: I believe it would. Each branch can maintain its own circulation policies and any features around inter-campus sharing can be turned off. There was an alternative set-up where each branch would have a completely separate install, only sharing an OPAC, which we did not examine.

Q: How do you manage inventory between [campuses]? You mentioned books from one campus are held until requested back to the home library.

A: Koha has both "home location" and "current location" for item records. Home location does not change. It is easy to run a report looking for items that have a different home than current location.

Q: Have you integrated Koha into any other campus systems?

A: We have not.

Q: What is your biggest savings by moving to Koha?

A: The software and its hosting fees are a tenth of our previous costs. We also save significantly on staff time because of the easy-to-use automation. 
Q: How doyou manage electronic resources? Do you manage e-books in Koha or use something else?

A: Currently, all e-books in Koha are unlimited simultaneous users, so no e-check-out feature has been researched by the staff. E-books in Koha work best when item records are created. One challenge is that Koha's bulk import tool does not allow you to add new elements to existing records, only replace. E-books held by both Southern and ULS are currently separate bibliographic records, but, in the future, we will likely use Koha's export tool to identify duplicate records, edit in MarcEdit by adding both institutions' URLs, and then re-import as replacement records.

\section{ASSESSMENT}

The Eastern Cluster Library has reduced costs, made staff training simpler, and is able to automate many formerly manual processes. Most problems the Cluster encountered during install and in the first year were due to not fully understanding how Koha structures and presents data, rather than a failure of Koha's features. With some adaptation, the Cluster staff has learned the new integrated library system and users are generally happy with the new service. Overall, Koha has been a success for the Cluster, meeting all the Cluster's key needs.

\section{WORKS CITED}

Krueger, Karl. 2007. “One Library under Three Roofs: The Exciting Sequel.” Atla Summary of Proceedings 61: 127-41.

Wartluft, David J. 2002. "One Library under Three Roofs: A Case Study." Atla Summary of Proceedings 56: 207-17. 


\section{ENDNOTES}

1 Early on, many staff were well-trained on what was then Endeavor Voyager. After the first few years, the Cluster stopped sending staff to biennial trainings. Since the early days, many people had retired or resigned in the last 15 years, taking with them a lot of the in-depth knowledge needed to keep the catalog running. 